\title{
Reassessing the Use of Inner-Core Hot Towers to Predict Tropical Cyclone Rapid Intensification*
}

\author{
XiaO-Yong Zhuge, Jie Ming, and Yuan Wang \\ School of Atmospheric Sciences, and Key Laboratory of Mesoscale Severe Weather of Ministry of \\ Education, Nanjing University, Nanjing, China
}

(Manuscript received 10 February 2015, in final form 22 June 2015)

\begin{abstract}
The hot tower (HT) in the inner core plays an important role in tropical cyclone (TC) rapid intensification (RI). With the help of Tropical Rainfall Measurement Mission (TRMM) data and the Statistical Hurricane Intensity Prediction Scheme dataset, the potential of HTs in operational RI prediction is reassessed in this study. The stand-alone HT-based RI prediction scheme showed little skill in the northern Atlantic (NA) and eastern and central Pacific (ECP), but yielded skill scores of $>0.3$ in the southern Indian Ocean (SI) and western North Pacific (WNP) basins. The inaccurate predictions are due to four scenarios: 1) RI events may have already begun prior to the TRMM overpass. 2) RI events are driven by non-HT factors. 3) The HT has already dissipated or has not occurred at the TRMM overpass time. 4) Large false alarms result from the unfavorable environment. When the HT was used in conjunction with the TC's previous 12-h intensity change, the potential intensity, the percentage area from 50 to $200 \mathrm{~km}$ of cloud-top brightness temperatures lower than $-10^{\circ} \mathrm{C}$, and the $850-200-\mathrm{hPa}$ vertical shear magnitude with the vortex removed, the predictive skill score in the SI was 0.56. This score was comparable to that of the RI index scheme, which is considered the most advanced RI prediction method. When the HT information was combined with the aforementioned four environmental factors in the NA, ECP, South Pacific, and WNP, the skill scores were $0.23,0.32,0.42$, and 0.42 , respectively.
\end{abstract}

\section{Introduction}

Anticipating the rapid intensification (RI) of a tropical cyclone (TC) has long been one of the greatest challenges for operational forecast centers around the world (Rappaport et al. 2009). With the National Hurricane Center (NHC 2008) elevating RI prediction to its top forecast priority, how to predict RI is gradually emerging as a hot topic in meteorological research.

During the past two decades, a number of studies have attempted to explain and forecast RI from the perspective of the large-scale environment. These studies found that warm sea surface temperature (SST; Shay et al. 2000; Chan et al. 2001), high ocean heat content

\footnotetext{
* Supplemental information related to this paper is available at the Journals Online website: http://dx.doi.org/10.1175/WAF-D-15-0024.s1.

Corresponding author address: Yuan Wang, School of Atmospheric Sciences, and Key Laboratory of Mesoscale Severe Weather of Ministry of Education, Nanjing University, Nanjing 210023, China. E-mail: yuanasm@nju.edu.cn
}

(OHC; Mainelli et al. 2008; Wada and Usui 2007; Shay and Brewster 2010), weak vertical wind shear (Gallina and Velden 2002; Wong and Chan 2004), and weak forcing from an upper-level trough or cold low (Molinari and Vollaro 1989; Molinari et al. 1995; Bosart et al. 2000; Hanley et al. 2001) are all favorable conditions for storms undergoing RI. More recently, an RI index (RII) was derived from the previous 12-h intensity change (PER), 200-hPa divergence, vertical wind shear, OHC, lower-level relative humidity, the strength and symmetry of inner-core convection, and the potential intensity (POT; Kaplan et al. 2010). The evaluations in Kaplan et al. (2010) for the northern Atlantic (NA) and eastern and central Pacific (ECP), as well as in Shu et al. (2012) for the western North Pacific (WNP), show that RII schemes are skillful relative to the climatology.

Nevertheless, the latest research shows that environmental factors are insufficient in terms of the conditions needed for RI (Hendricks et al. 2010). RI is more likely controlled by internal dynamical processes (Hendricks 2012). Some important internal processes affecting TC development include eyewall instability and inner-core 
mixing (Schubert et al. 1999), the eyewall replacement cycle (Willoughby et al. 1982), and hot towers (HTs). Among these factors, The HT-based RI mechanism is the one currently receiving the most attention. HTs are the towering high clouds that penetrate the tropopause. These towers are referred to as "hot" because a large quantity of heat is released inside them (Riehl and Malkus 1958). According to the results of numerical simulations and field observations, upper-level outflow from the HT top forces the air to subside inside the eye and a warm core is produced (Wang and Wang 2014). The eye's surface pressure then drops quickly through hydrostatic adjustment (Heymsfield et al. 2001; Schubert et al. 2007; Guimond et al. 2010; Zhang and Chen 2012). To adapt to the central pressure's sudden change and maintain the gradient wind balance, the tangential wind speeds up (Willoughby 1998), and thus the TC intensity rapidly increases. Kelley and Halverson (2011) estimated that a HT-like convective burst might cause TC intensification of $17-31$ knots $\left(\mathrm{kt} ; 1 \mathrm{kt}=0.51 \mathrm{~m} \mathrm{~s}^{-1}\right)$. Another acceptable hypothesis is the upscale vorticity growth mechanism relevant to HTs possessing strong vertical vorticity in their cores, or "vortical" HTs (VHTs; Hendricks et al. 2004). According to Montgomery et al. (2006), the continuing VHTs generate a system-scale latent heating process and, meanwhile, small-scale vorticity anomalies. This locally vorticity-rich environment supports a quasisteady heating in the system-scale circulation. Ultimately, a thermodynamically direct toroidal circulation pattern is generated and accordingly the tangential wind speed increases.

Meanwhile, some numeric and observation studies indicate that HTs are a by-product of the RI process (Rogers 2010). Nolan and Grasso (2003) documented that asymmetric intense convection (e.g., HTs) has a slight impact on TC intensification. Nguyen et al. (2011) indicated through a simulation of Hurricane Katrina (2005) that vortices vacillate between almost symmetric and highly asymmetric phases, and the symmetric-toasymmetric transition was triggered by a combination of barotropic and convective instability, yielding an asymmetric eyewall inlaid with HTs, and weaker intensification rates. McFarquhar et al. (2012) found that the area of HT-like convective bursts did not strongly increase before RI, but continually increased after RI, in a simulation of Hurricane Dennis (2005). Nguyen and Molinari (2012) demonstrated that inner-core HTs might develop toward the end of the RI period, based on the observation of Hurricane Irene (1999).

To help resolve the debate of whether HTs are a precursor or a by-product of the RI process, climatological studies with satellite observations have been implemented. Tao and Jiang (2013) used data from the 11-yr Tropical Rainfall Measuring Mission (TRMM) TC Precipitation Feature database (TCPF; Jiang et al. 2011) to show that the probability of RI was $17 \%$ among 615 TCPFs with inner-core HTs. Kelley et al. (2004) examined $6 \mathrm{yr}$ of TRMM data and found $71 \%$ of 35 cases with a maximum $20-\mathrm{dB} Z$ echo height $\left(H_{20 \mathrm{~dB} Z}\right)$ of $\geq 14.5 \mathrm{~km}$ (as a proxy for HTs), $46 \%$ of 104 cases with an $H_{20 \mathrm{dBZ}}$ of $10-14.25 \mathrm{~km}$, and $13 \%$ of 24 cases with an $H_{20 \mathrm{~dB} Z}$ of $<10 \mathrm{~km}$, underwent intensification and, thus, concluded that the link between HTs and TC intensification was significant. However, according to the data provided by Kelley et al. (2004), only $32.9 \%$ of a total of 76 intensified cases possessed HTs. Jiang (2012), using $11 \mathrm{yr}$ of TRMM data, further examined the relationship between TC RI and inner-core HTs and found the increase in the probability of RI for TCs with inner-core HTs to be only $3.3 \%$ compared to the climatological mean. Thus, it was argued that HTs were neither a necessary nor sufficient condition for RI. Monette et al. (2012) proposed a "tropical overshooting tops" (TOT; as a proxy for HT) detection algorithm and assessed the potential of TOT information in predicting TC RI in the NA basin by using Geostationary Operational Environmental Satellite-East (GOES-E) imagery. The results showed that the TOT-based RI scheme was comparatively less accurate than the RII scheme. The existing results of climatological assessments seem less convincing for both sides of the debate.

During the above climatological assessments, little attention was paid to the heating efficiency of HTs. In fact, even if the HT hypothesis is reliable, the heating efficiency of HTs can determine whether or not a TC finally undergoes RI. Several recent idealized modeling studies have demonstrated that the heating efficiency varies with HT location, and that of HTs within the radius of maximum wind (RMW) is highest (e.g., Nguyen and Molinari 2012). Also, the large-scale environment is involved in the heating. For example, through the ventilation effect of the strong vertical shear, the warm and moist air released by HTs can rapidly diffuse into the environment (e.g., Gray 1968; Frank and Ritchie 2001); the upper-level warm core becomes weak and eventually the TC's development is suppressed. Therefore, combining HT information with environment factors favorable for RI can potentially provide a way to improve RI prediction. Additionally, the different TCenvironment interactions in different ocean basins may alter the heating efficiency of HTs.

Based on the above understanding, this paper revisits climatological satellite observations, investigates the potential of HTs in operational RI prediction, and provides new indirect evidence for the HT hypothesis. The remainder of the paper is organized as follows. The data 

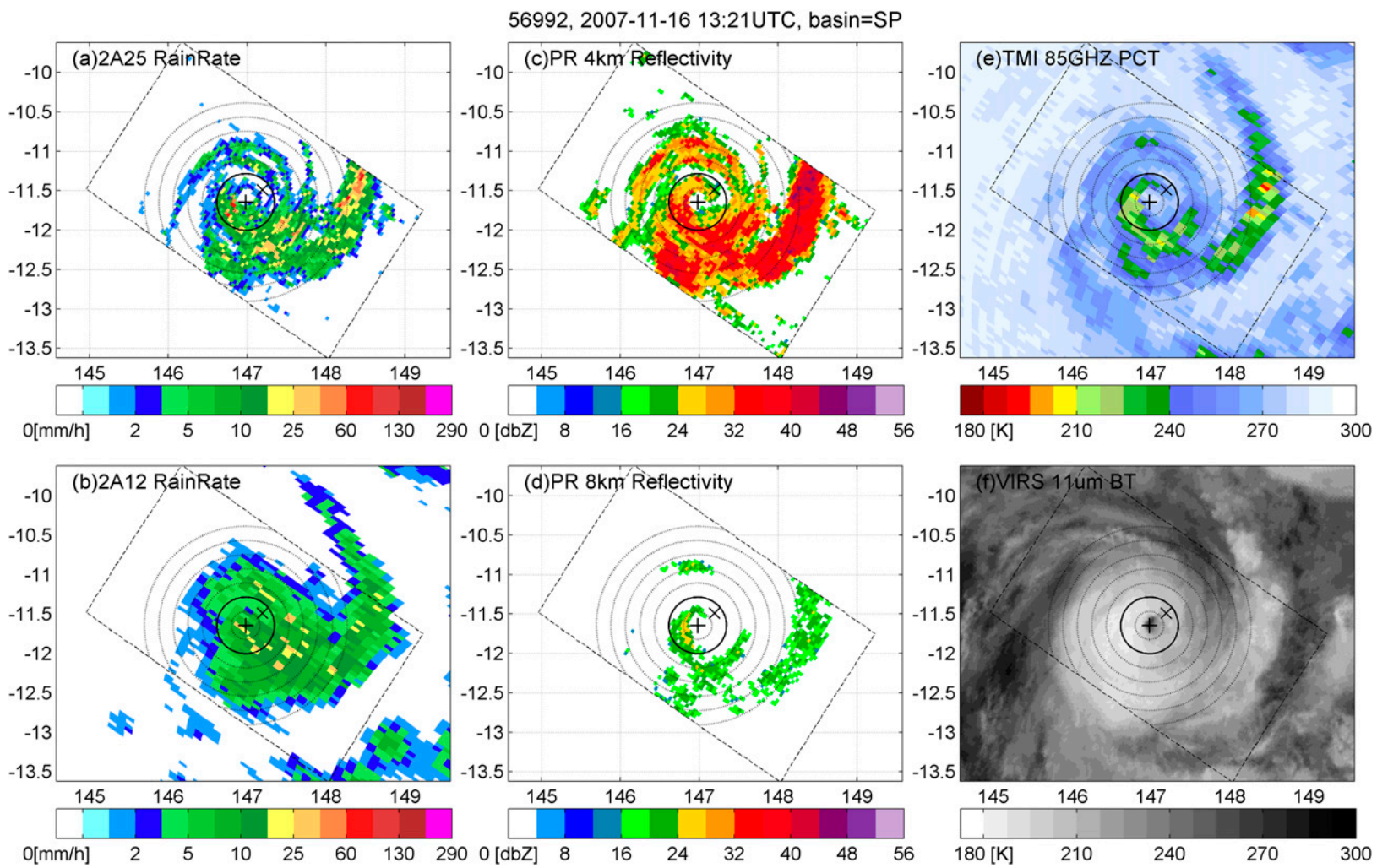

FIG. 1. Observations from TC Guba (2008), TRMM orbit 56992, at 1321 UTC 16 Nov 2007. The dashed rectangle indicates the edge of the PR swath. The multiplication $(\times)$ and plus $(+)$ signs represent the interpolated and modified TC center, respectively. The dashed circles represent $20-\mathrm{km}$ increments radially outward from the TC center and the solid circles indicate the outermost radius of the inner core: (a) 2A25 rain rate, (b) $2 \mathrm{~A} 12$ rain rate, (c) PR $4 \mathrm{~km}$ reflectivity, (d) PR $8 \mathrm{~km}$ reflectivity, (e)TMI $85 \mathrm{GHz}$ PCT, and (f) VIR $11 \mu \mathrm{m}$ BT.

and preprocessing methods are described in section 2 . The predictive power of stand-alone HTs is evaluated by basin in section 3. Section 4 analyzes the factors affecting the predictive power of HTs, and section 5 presents the reassessment. Conclusions and the future outlook are given in section 6 .

\section{Data and preprocessing}

The University of Utah TRMM Precipitation Feature (PF) level 1 dataset (Liu et al. 2008) was used in this study. Level-1C21 Precipitation Radar (PR) reflectivity profiles, level-2A25 PR rain products, level-1B11 TRMM Microwave Imager (TMI) polarization corrected temperatures (PCTs), level-2A12 TMI rain products, and level-1B01 Visible and Infrared Scanner (VIRS) brightness temperatures of the same orbit were collocated and interpolated to PR coordinates. A simple parallax correction for TMI data was also conducted to improve the position accuracy of deep convective cells.

The information on TC center, intensity, and nature was obtained from the International Best Track Archive for Climate Stewardship (IBTrACS; Knapp et al. 2010), v03r05, which compiles the 6-h-resolution best-track data from the National Hurricane Center (NHC) for the Atlantic Ocean and ECP basins and the Joint Typhoon Warning Center (JTWC) for the Indian Ocean, WNP, and South Pacific (SP) basins. The TC intensity and center location for each TRMM observation were then linearly interpolated to the scan time. Similar to Hence and Houze (2011), the TC center could also be manually adjusted if suggested by PR reflectivity, VIRS $11-\mu \mathrm{m}$ brightness temperature, and the surface rain rate. Figure 1 shows an example of the position determination for TC Guba (2008) in the SP on 16 November 2007. This overpass was ideal because the convection was roughly concentric. In the middle-level PR reflectivity (Fig. 1c) and $11-\mu \mathrm{m}$ brightness temperature (Fig. 1f), the TC eye is clear, warm, and surrounded by intense convection with $>30-\mathrm{dB} Z$ reflectivity. However, the interpolated center is on the outermost edge of the eyewall, and so the TC center should be moved to the place where the TC eye is located. In cases of noneye TCs with a curved cloud band, the TC center should 
be near the inner edge of the curve band (Dvorak 1995). The present study is not concerned with TCs of intensity below that of tropical storm strength (i.e., 1-min maximum wind speed $<34 \mathrm{kt}$ ), as their cloud systems are incomplete and their center position determinations immature.

An accurate TC center is important for judging whether or not an HT is within the inner core. Here, the inner core was defined as the eyewall region for TCs with an eye and the near-center convection for TCs without an eye. Specifically, in this study, the outer boundary of the inner-core region was subjectively determined as the outer edge of the largest horizontal gradient of TRMM PR reflectivity and TMI $85-\mathrm{GHz}$ PCT. Figure 1 also shows an example of the partition of inner-core and rainband regions for TC Guba (2008). The radius of the TC eye is about $20 \mathrm{~km}$, and the eyewall convection-as indicated by the $30-\mathrm{dB} Z$ middle-level reflectivity (Fig. 1c) and 240-K microwave PCT (Fig. 1e) contours-extends up to the $40-\mathrm{km}$ radius. Therefore, the inner-core boundary was determined to be $40 \mathrm{~km}$ in this case. Because the swath width of TRMM PR is only $247 \mathrm{~km}$, not all TRMM TC overpasses can capture the $\mathrm{TC}$ in full. The TC overpasses where the distance between the TC center and PR swath center was more than $100 \mathrm{~km}$ were removed so that only those that captured at least $60 \%$ of the inner-core region were included. There were 1033 overpasses that met all the conditions during the $11 \mathrm{yr}$ from 2002 to $2012 .^{1}$ The mean and standard deviation of the radial extent of the inner-core region were 65.55 and $20.42 \mathrm{~km}$, respectively, for all of these 1033 TRMM TC overpasses.

The environmental parameters used in this study were extracted from the Statistical Hurricane Intensity Prediction Scheme (SHIPS; DeMaria et al. 2005). The time (6 hourly) nearest to the TRMM overpass was used. Some SHIPS variables are computed using different algorithms for different basins. Taking the maximum potential intensity (MPI) as an example, this is determined using an adjusted inner-core SST that reflects the influence of TC speed and latitude (Cione et al. 2010) for the NA basin; however, the weekly gridded $1^{\circ} \times 1^{\circ}$ Reynolds SST dataset (RSST; Reynolds and Smith 1993) is used for other basins. Also, the SHIPS

\footnotetext{
${ }^{1}$ In total, there were 904 TCs and 16084 best-track records with wind intensity above tropical storm strength during the $11 \mathrm{yr}$, among which 854 TCs and 3680 records have been observed by wide-swath instruments on board TRMM, such as TMI and VIRS (with swath width of $\sim 800 \mathrm{~km}$ ) at least once, and 510 TCs and 938 records have been sufficiently covered by PR. The sampling rate of $\mathrm{PR}$ is only $\sim 5 \%$. It may increase if more spaceborne radars are involved.
}

variables are set to missing for extratropical cases, and thus the TRMM TC overpasses where a TC underwent extratropical transition within $+24 \mathrm{~h}$ were removed. In addition, a prerequisite is that a TC must remain over water. Therefore, those cases with land interaction within $+24 \mathrm{~h}$ were also removed.

Ultimately, the filtered dataset yielded 843 TRMM TC overpasses, the geographic distribution of which is presented in Figs. 2a and 2b. Table 1 shows the population and fraction of samples with different initial TC intensities in each TC-prone basin. More than one-third of the TC samples and nearly one-half of the category $3-$ 5 typhoons were distributed in the WNP. The number of tropical storms in the ECP was less than in the southern Indian Ocean (SI) and NA basins, but category 3-5 hurricanes were more abundant in the ECP than in the SI and NA basins. The samples with intensity above tropical storm strength in the northern Indian Ocean (NI) and South Atlantic (SA) basin were rare and thus considered to be unrepresentative. Therefore, the statistical results of the NI and SA basins are not included in the following analysis and discussion.

RI is defined as the maximum wind speed intensity increase equal to or greater than a certain threshold (typically 25,30 , or $35 \mathrm{kt}$ ) in a $24-\mathrm{h}$ period. Similar to Kaplan and DeMaria (2003) and Jiang and Ramirez (2013), the 30-kt threshold is chosen in the present paper. Accordingly, 80 overpasses were distinguished as RI samples and their geographic distributions are shown in Fig. 2c. Table 2 summarizes the number and fraction of RI samples in each basin. The fractions of RI samples were equal to $9.49 \%$ globally, and varied across the basins. Among the basins, NA had the highest (10.87\%) fraction of RI samples, and ECP had the lowest (6.56\%). The fraction in NA (ECP) was slightly higher than (similar to) that in Kaplan et al. (2010).

\section{The predictive power of stand-alone HTs}

\section{a. The proxy for HTs}

According to the definition, the HT top should reach or penetrate the tropopause. A cloud top is the uppermost edge of echo with 0 (or less) $\mathrm{dB} Z$ in the radar image. However, the minimum reflectivity TRMM can measure is $17-20 \mathrm{~dB} Z$ (Liu et al. 2008). Only clouds with precipitation-sized particles are likely to attain $20-\mathrm{dB} Z$ reflectivity, so the detection method using $H_{20 \mathrm{~dB} Z}$ above the tropopause as a proxy for HT will miss the majority of HT events. Luo et al. (2008) analyzed the internal vertical structure of penetrating convection (i.e., HTs) by using the observations of the CloudSat $94-\mathrm{GHz}$ cloud profile radar (CPR), and found the "cold high" (i.e., the mature) type of tropical penetrating convection has an 


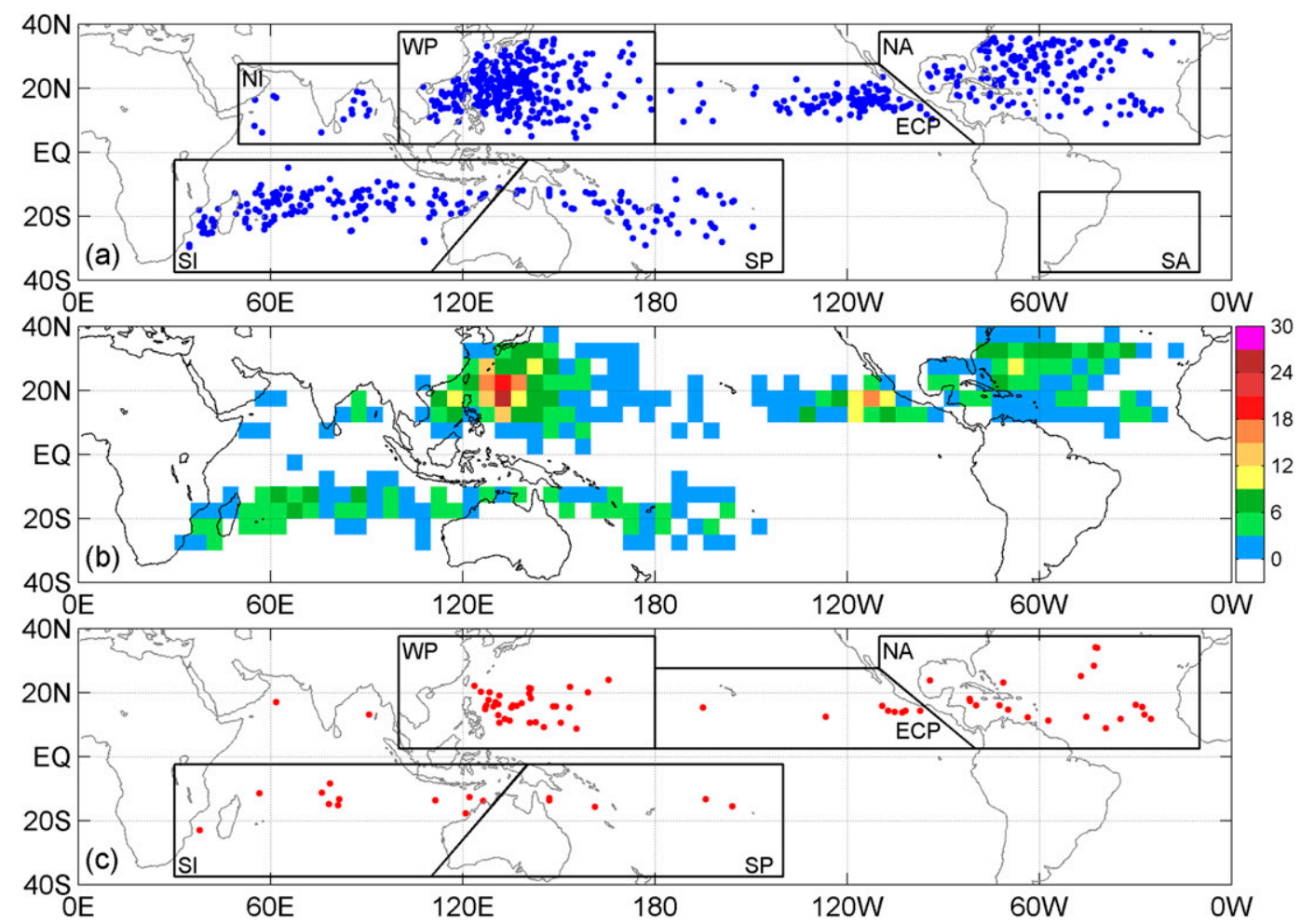

FIG. 2. Geographic distribution of the (a) 843 TRMM TC overpasses, (b) overpass number density, and (c) TC overpasses undergoing RI. The overpass number density is defined as the total number of TRMM TC overpasses in each $5^{\circ} \times 5^{\circ}$ bin. The borders of seven basins (NA, SA, ECP, NI, SI, SP, and WNP) are also indicated in (a).

average cloud top $(-28 \mathrm{~dB} Z)$ of $16.67 \mathrm{~km}$, and the maximum heights of 0 and $10 \mathrm{~dB} Z$ are 15.03 and $11.95 \mathrm{~km}$, respectively. This means $H_{20 \mathrm{~dB} Z}$ is at least $3 \mathrm{~km}$ lower than the tropopause.

The reference heights of 14 (e.g., Alcala and Dessler 2002; Tao and Jiang 2013) or $14.5 \mathrm{~km}$ (e.g., Kelley et al. 2004; Jiang 2012) have also been previously used to detect HTs. A constant reference height has a shortcoming because the level of the tropopause varies with latitude and basin (Gettelman et al. 2011). It can be seen from Fig. 2a that the latitudes of TCs in the NA are higher than those in other basins, and thus the tropopause for TCs in the NA should be lower. Table 3 summarizes the average latitude and tropopause level ( $Z_{\text {trop }}$ ) of TRMM TC overpasses in each basin. The $Z_{\text {trop }}$ information was obtained from $2.5^{\circ}$-resolution National Centers for Environmental Prediction-National Center for Atmospheric Research (NCEP-NCAR) reanalyses data (Kalnay et al. 1996). The average latitude in the NA was $5^{\circ}$ higher than that in the WNP, and $9^{\circ}$ higher than those in other basins. Therefore, the average $Z_{\text {trop }}$ was $1 \mathrm{~km}$ lower than that in the SI and SP. The average $Z_{\text {trop }}$ in the ECP was at least $0.6 \mathrm{~km}$ lower than that in the SI and SP. Therefore, the height threshold of $14.5 \mathrm{~km}$ used in previous publications is not appropriate for TCs in the NA and ECP.

This study uses $H_{20 \mathrm{~dB} Z}$ greater than $Z_{\text {trop }}=-2.5 \mathrm{~km}$ as a proxy for HT. As a result, the height threshold in the $\mathrm{SP}$ was $14.33 \mathrm{~km}$ on average. Because the vertical resolution of PR is $0.25 \mathrm{~km}$, the $H_{20 \mathrm{~dB} Z}$ of the majority of

TABLE 1. Population and fraction of samples with different initial TC intensities in each TC-prone basin.

\begin{tabular}{lcccccccc}
\hline \hline & NA & SA & ECP & NI & SI & SP & WNP & Globe \\
\hline Total No. of samples & 184 & 0 & 122 & 15 & 141 & 61 & 320 & 843 \\
No. of tropical storm (TS) & 98 & 0 & 55 & 8 & 75 & 35 & 135 & 406 \\
Fraction of TS samples (\%) & 53.26 & - & 45.08 & 53.33 & 53.19 & 57.38 & 42.19 & 48.16 \\
No. of category 1-2 samples & 61 & 0 & 37 & 4 & 46 & 12 & 101 & 261 \\
Fraction of category 1-2 samples (\%) & 33.15 & - & 30.33 & 26.67 & 32.62 & 19.67 & 31.56 & 30.96 \\
No. of category 3-5 samples & 25 & 0 & 30 & 3 & 20 & 14 & 84 & 176 \\
Fraction of category 3-5 samples (\%) & 13.59 & - & 24.59 & 20.00 & 14.8 & 22.95 & 26.25 & 20.88 \\
\hline
\end{tabular}


TABLE 2. Population and fraction of TC samples undergoing RI in each basin.

\begin{tabular}{|c|c|c|c|c|c|c|}
\hline & NA & ECP & SI & SP & WNP & Globe \\
\hline No. of RI samples & 20 & 8 & 11 & 5 & 34 & 80 \\
\hline $\begin{array}{l}\text { Fraction of RI } \\
\text { samples }(\%)\end{array}$ & 10.87 & 6.56 & 7.80 & 8.20 & 10.63 & 9.49 \\
\hline
\end{tabular}

HTs occurring in the SP still has to reach $14.5 \mathrm{~km}$. In the $\mathrm{NA}$, the $20-\mathrm{dB} Z$ echo top should be above $13.25 \mathrm{~km}$.

The probabilities of HT occurrence as a function of the initial TC intensity are shown in Fig. 3. The tropical storms and category 1-2 hurricanes/typhoons accounted for nearly the same probability of inner-core HTs, while the category 3-5 hurricanes/typhoons accounted for the least probability (except in the NA). If the initial intensity is not considered, the TCs in the SI basin had the highest $(44.68 \%)$ probability of HT occurrences, and those in the SP basin had the lowest $(37.70 \%)$. Table 4 displays the number and probability of RI for samples with and without inner-core HTs in each basin. Among the samples with inner-core HTs, the probability of RI occurrence was highest $(18.52 \%)$ for the WNP and lowest $(7.41 \%)$ for the ECP. However, among the samples without inner-core HTs, the probability of RI was highest (10.48\%) for the NA and lowest $(3.85 \%)$ for the SI. Globally, the increase in the probability of RI for TCs with inner-core HTs was only $4.3 \%$ compared to the climatological mean, which is close to the statistical results of Jiang (2012). When each basin was specifically analyzed, the probability of RI for TCs with inner-core HTs in the WNP increased by $7.9 \%$ compared to the climatological mean, but only by $0.5 \%$ and $0.8 \%$ in the NA and ECP, respectively.

\section{b. Skill score}

To evaluate the skill of the RI forecast, four metrics (Wilks 2006) were used, namely, the probability of detection (POD), the false alarm ratio (FAR), the probability of false detection (POFD; also known as the false alarm rate), and the Peirce skill score (PSS). Their definitions are as follow:

$$
\begin{aligned}
\text { POD } & =\frac{\text { Hit }}{\text { Hit }+ \text { Miss }}, \\
\text { FAR } & =\frac{\text { False_alarm }}{\text { Hit }+ \text { False_alarm }}, \\
\text { POFD } & =\frac{\text { False_alarm }}{\text { Correct_negative }+ \text { False_alarm }}, \text { and } \\
\text { PSS } & =\text { POD }- \text { POFD. }
\end{aligned}
$$

In Eqs. (1)-(4), Hit is the number of RI cases that are correctly forecasted, Miss is the number of RI cases that are
TABLE 3. Averaged latitude (LAT) and tropopause level $\left(Z_{\text {trop }}\right)$ of TRMM TC overpasses in each basin. Note that the averaged $Z_{\text {trop }}$ results in NA and ECP are lowest (shown in boldface).

\begin{tabular}{lccccc}
\hline \hline & NA & ECP & SI & SP & WNP \\
\hline LAT $\left(^{\circ}\right)$ & 25.95 & 16.61 & 16.88 & 17.34 & 20.12 \\
$Z_{\text {trop }}(\mathrm{km})$ & $\mathbf{1 5 . 6 0}$ & $\mathbf{1 6 . 0 7}$ & 16.70 & 16.83 & 16.48 \\
\hline
\end{tabular}

forecasted not to occur, False_alarm is defined as the number of times RI is forecasted but does not occur, and Correct_negative is the number of times RI is forecasted not to occur and does not occur. POD is $100 \%$ in a perfect forecast and $0 \%$ in a worst-case forecast. FAR and POFD are equal to $0 \%$ in a perfect forecast and $100 \%$ in a worstcase forecast. Since, POFD $=1 /\{$ (Correct_negative $/$ Hit $)$ $[(1 / \mathrm{FAR})-1)]+1\}$, POFD increases as FAR increases. PSS is 1 in a perfect forecast, 0 in a random forecast, and -1 in a worst-case forecast.

The PODs, FARs, POFDs, and PSSs of RI prediction with stand-alone HTs in each basin are presented in Fig. 4. The results of the climatological surveys mentioned in the introduction section are presented in Table 5 for comparison. It can be seen that the predictive abilities of HTs varied in the different TC-prone basins. In the NA and ECP, the PODs were both less than $50 \%$ and the FARs were the highest. Thus, the PSSs were the lowest, at only 0.02 and 0.06 , respectively. This means that the predictive power of stand-alone HTs for the RI prediction is very weak in these two basins. However, PSSs of more than 0.2 were obtained in the other three basins. In the WNP in particular, the PSS reached 0.35 with stand-alone HTs. The global average PSS was 0.21 , which is close to the results in Monette et al. (2012) and Jiang (2012) (see Table 5).

Four possible scenarios may explain the basin variability: 1) the subjective determination scheme for the inner-core outermost radius and the coarse resolution of the NCEP-NCAR reanalyses data may have led to sampling errors, 2) the quality of the best-track dataset was different for different basins (Schreck et al. 2014), 3) the differences in TC-environment interactions

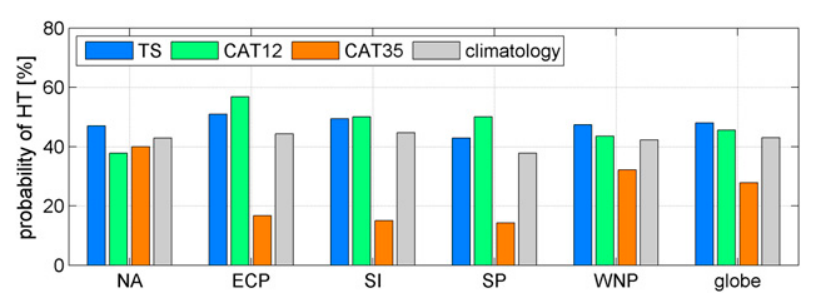

FIG. 3. Probabilities of HT occurrences as a function of different initial TC intensities: TS (blue), category 1-2 (green), category 3-5 (orange), and climatology (gray) for (from left to right) five basins (NA, ECP, SI, SP, and WNP) and the globe. 
TABLE 4. Number and probability of RI events for samples with and without inner-core HTs in each basin.

\begin{tabular}{|c|c|c|c|c|c|c|}
\hline & NA & ECP & SI & SP & WNP & Globe \\
\hline No. of samples with inner-core HTs & 79 & 54 & 63 & 23 & 135 & 363 \\
\hline No. of samples without inner-core HTs & 105 & 68 & 78 & 38 & 185 & 480 \\
\hline No. of RI samples with inner-core HTs & 9 & 4 & 8 & 3 & 25 & 50 \\
\hline Probability of RI for samples with HTs (\%) & 11.39 & 7.41 & 12.70 & 13.04 & 18.52 & 13.77 \\
\hline No. of RI samples without inner-core HTs & 11 & 4 & 3 & 2 & 9 & 30 \\
\hline Probability of RI for samples without HTs (\%) & 10.48 & 5.88 & 3.85 & 5.26 & 4.86 & 6.25 \\
\hline
\end{tabular}

among the different ocean basins may have altered the heating efficiency of HTs, and 4) apart from HTs, there could have been other factors driving or maintaining storm development. The third and fourth scenarios are discussed in detail in section 4 .

A comparison between the HT-based scheme and RII scheme is also shown in Fig. 4. The PSSs for the RII scheme used in Kaplan et al. (2010) for the NA and ECP were 0.53 and 0.59 , respectively, indicating that the RII scheme is still the most advanced RI prediction method. The RII scheme used in Shu et al. (2012) for the WNP yielded a PSS of 0.36 , and was slightly better than the stand-alone HT scheme.

\section{Influential factors}

According to Eq. (4), a low PSS results from a low POD and/or a high POFD. This section analyzes the factors influencing the predictive power of HTs from the perspective of both POD and POFD.
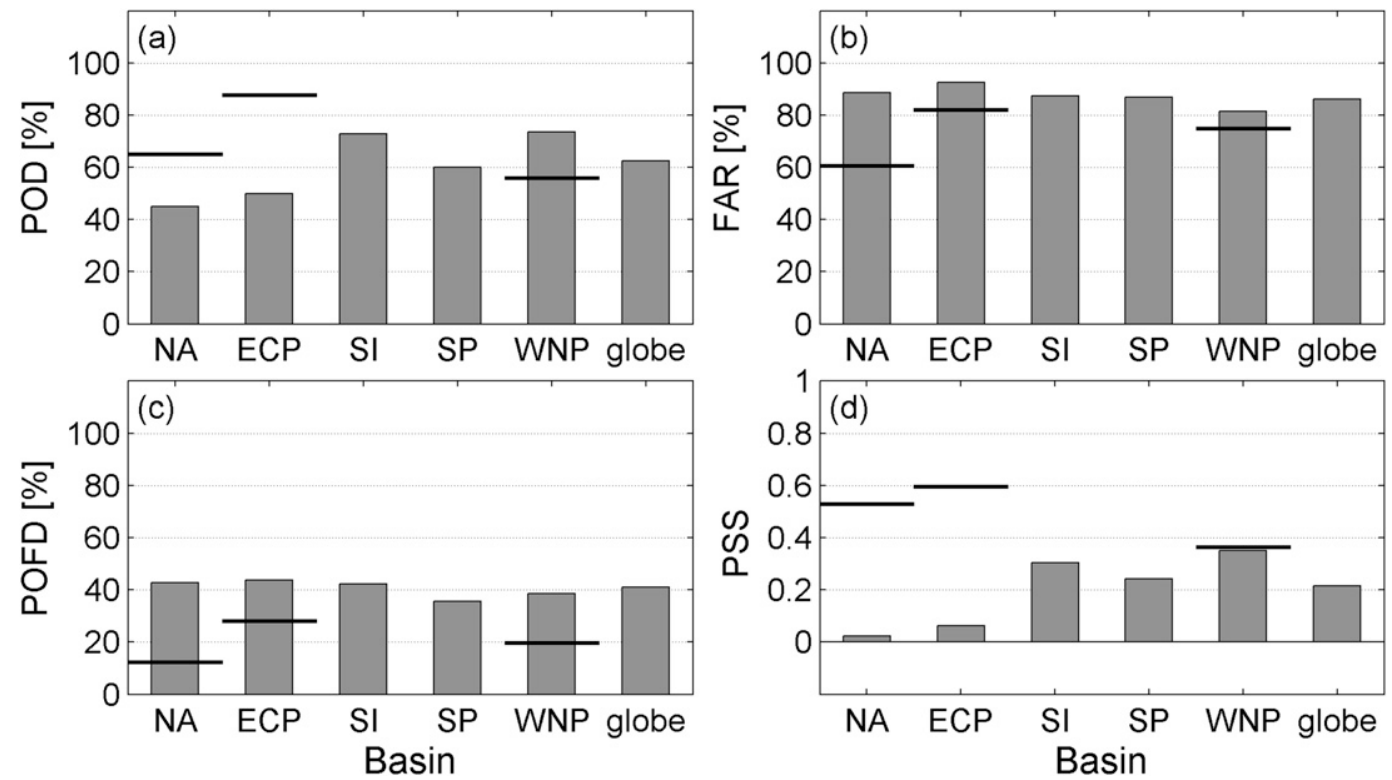

FIG. 4. (a) PODs, (b) FARs, (c) POFDs, and (d) PSSs of RI prediction with stand-alone HTs in five basins (NA, ECP, SI, SP, and WNP) and the globe. The statistical results of RI prediction with RII schemes are also shown (black solid line). The RII schemes for NA and ECP are described in Kaplan et al. (2010) and the RII scheme for WNP in Shu et al. (2012). 
TABLE 5. Results from climatological assessments using satellite observations.

\begin{tabular}{|c|c|c|c|c|c|c|}
\hline Reference & Dataset used & Proxy for HT & $\begin{array}{l}\text { Basin of } \\
\text { interest }\end{array}$ & HT location & Focus & Conclusion \\
\hline Tao and Jiang (2013) & $11 \mathrm{yr}$ of TRMM & $H_{20 \mathrm{~dB} Z} \geq 14 \mathrm{~km}$ & Globe & Inner core $(\sim 82 \mathrm{~km})$ & 30-kt RI & $\mathrm{FAR}=83 \%$ \\
\hline Kelley et al. (2004) & $6 \mathrm{yr}$ of TRMM & $H_{20 \mathrm{~dB} Z} \geq 14.5 \mathrm{~km}$ & Globe & Eyewall & Intensification & $\begin{aligned} \text { POD } & =32.9 \% \\
\text { FAR } & =29 \%, \\
\text { PSS } & =0.214\end{aligned}$ \\
\hline Jiang (2012) & $11 \mathrm{yr}$ of TRMM & $H_{20 \mathrm{~dB} Z} \geq 14.5 \mathrm{~km}$ & Globe & Inner core $(\sim 87 \mathrm{~km})$ & 30-kt RI & $\begin{aligned} \text { POD } & =45.6 \% \\
\text { FAR } & =90.4 \%, \\
\text { PSS } & =0.167\end{aligned}$ \\
\hline \multirow[t]{3}{*}{ Monette et al. (2012) } & $\begin{array}{l}\text { GOES-E during } \\
\text { 2006-07 }\end{array}$ & TOT & NA & $\begin{array}{l}\text { Within } 300 \mathrm{~km} \text { of TC } \\
\text { center }\end{array}$ & 25-kt RI & $\begin{aligned} \text { POD } & =48.3 \%, \\
\text { FAR } & =81.6 \%, \\
\text { PSS } & =0.238\end{aligned}$ \\
\hline & & & & & 30-kt RI & $\begin{aligned} \text { POD } & =45.8 \% \\
\text { FAR } & =85.5 \% \\
\text { PSS } & =0.206\end{aligned}$ \\
\hline & & & & & 35-kt RI & $\begin{aligned} \text { POD } & =23 \% \\
\text { FAR } & =97 \% \\
\text { PSS } & =-0.04\end{aligned}$ \\
\hline
\end{tabular}

overpasses were classified as RI cases according to the 6-hourly best-track data. However, we should not hastily declare the prediction of the first overpass as a miss, since the first overpass was too near the actual onset of RI. Another example is TC Dennis (2005). The first overpass captured moderate convection only (see row 4 in Table 6), but was followed by an $\mathrm{RI}$ episode. The intensification rate in the first few hours was low [10 kt $(12 \mathrm{~h})^{-1}$; equal to $20 \mathrm{kt}(24 \mathrm{~h})^{-1}$ ] until $15 \mathrm{~h}$ later, when an HT erupted (see row 5 in Table 6). Therefore, the majority of the intensification occurred from the moment of HT occurrence through the forthcoming $24 \mathrm{~h}$ for the first overpass of Dennis (2005).

The failure to identify the RI of Hurricane Wilma (2005) can also be explained by this scenario. Although the convection was not sufficiently intense at the onset of RI (see row 6 in Table 6), an HT-like

TABLE 6. List of all 20 of the RI cases in NA. The RI starting and ending times are at 6 -h resolution. The initial intensity and the intensity changes in the past $24 \mathrm{~h}(-24 \mathrm{~h})$, the forthcoming $12 \mathrm{~h}(+12 \mathrm{~h})$, and the forthcoming $24 \mathrm{~h}(+24 \mathrm{~h})$ have been interpolated to the TRMM scan time, and the continuing RI is defined as the RI event beginning at least $6 \mathrm{~h}$ prior to the TRMM overpass. Individual factors that either did or did not satisfy their corresponding definitions are shown with check $(\sqrt{ })$ and multiplication $(\times)$ symbols, respectively.

\begin{tabular}{|c|c|c|c|c|c|c|c|c|c|}
\hline TC (year) & $\begin{array}{l}\text { Time and } \\
\text { date of } \\
\text { overpass }\end{array}$ & $\begin{array}{l}\text { Initial } \\
\text { intensity } \\
(\mathrm{kt})\end{array}$ & $\begin{array}{l}\text { Intensity } \\
\text { change in } \\
-24 \mathrm{~h}(\mathrm{kt})\end{array}$ & $\begin{array}{l}\text { Intensity } \\
\text { change in } \\
+12 \mathrm{~h}(\mathrm{kt})\end{array}$ & $\begin{array}{l}\text { Intensity } \\
\text { change in } \\
+24 \mathrm{~h}(\mathrm{kt})\end{array}$ & $\begin{array}{l}\text { Hours from } \\
\text { the RI } \\
\text { starting time }\end{array}$ & $\begin{array}{c}\text { Hours to } \\
\text { the RI } \\
\text { ending time }\end{array}$ & $\begin{array}{c}\text { Continuing } \\
\text { RI }\end{array}$ & HT \\
\hline Danielle (2004) & 1527 UTC 14 Aug & 51 & 20 & 20 & 32.5 & 15 & 27 & $\sqrt{ }$ & $\times$ \\
\hline Ivan (2004) & 1538 UTC 4 Sep & 53 & 10 & 10 & 45 & 4 & 38 & $x$ & $\sqrt{ }$ \\
\hline Karl (2004) & 0826 UTC 17 Sep & 52 & 22.5 & 10 & 35 & 8 & 34 & $\sqrt{ }$ & $\times$ \\
\hline Dennis (2005) & 0639 UTC 6 Jul & 51 & 20 & 10 & 30 & 1 & 53 & $x$ & $\times$ \\
\hline Dennis (2005) & 2130 UTC 6 Jul & 66 & 22.5 & 20 & 45 & 16 & 38 & $\sqrt{ }$ & $\sqrt{ }$ \\
\hline Wilma (2005) & 1754 UTC 17 Oct & 45 & 15 & 15 & 30 & 0 & 48 & $x$ & $x$ \\
\hline Dean (2007) & 1322 UTC 15 Aug & 51 & 15 & 10 & 30 & 1 & 23 & $\times$ & $\times$ \\
\hline Felix (2007) & 1528 UTC 1 Sep & 56 & 27.5 & 20 & 47.5 & 21 & 45 & $\sqrt{ }$ & $\sqrt{ }$ \\
\hline Dolly (2008) & 1244 UTC 22 Jul & 56 & 10 & 10 & 30 & 1 & 23 & $x$ & $x$ \\
\hline Hanna (2008) & 2147 UTC 31 Aug & 43 & -5 & 12.5 & 30 & 4 & 26 & $\times$ & $\sqrt{ }$ \\
\hline Paloma (2008) & 0432 UTC 7 Nov & 65 & 30 & 15 & 45 & 5 & 37 & $\times$ & $\sqrt{ }$ \\
\hline Paloma (2008) & 1244 UTC 7 Nov & 76 & 35 & 25 & 50 & 13 & 29 & $\sqrt{ }$ & $\sqrt{ }$ \\
\hline Fred (2009) & 2324 UTC 7 Sep & 34 & - & 20 & 35 & 5 & 43 & $x$ & $x$ \\
\hline Julia (2010) & 0315 UTC 14 Sep & 53 & 12.5 & 22.5 & 47.5 & 15 & 39 & $\sqrt{ }$ & $\times$ \\
\hline Julia (2010) & 1807 UTC 14 Sep & 80 & 35 & 30 & 35 & 30 & 24 & $\sqrt{ }$ & $\sqrt{ }$ \\
\hline Tomas (2010) & 2036 UTC 29 Oct & 49 & - & 12.5 & 32.5 & 15 & 27 & $\sqrt{ }$ & $\times$ \\
\hline Gordon (2012) & 0203 UTC 18 Aug & 62 & 5 & 20 & 30 & 8 & 22 & $\sqrt{ }$ & $\times$ \\
\hline Gordon (2012) & 0341 UTC 18 Aug & 63 & 5 & 20 & 30 & 10 & 20 & $\sqrt{ }$ & $\sqrt{ }$ \\
\hline Kirk (2012) & 1809 UTC 29 Aug & 45 & 15 & 10 & 30 & 0 & 36 & $x$ & $\times$ \\
\hline Michael (2012) & 1500 UTC 5 Sep & 57 & 15 & 30 & 40 & 15 & 27 & $\sqrt{ }$ & $\sqrt{ }$ \\
\hline
\end{tabular}


TABLE 7. As in Table 6, but for all eight of the RI cases in the ECP.

\begin{tabular}{|c|c|c|c|c|c|c|c|c|c|}
\hline TC (year) & $\begin{array}{l}\text { Time and } \\
\text { date of } \\
\text { overpass }\end{array}$ & $\begin{array}{l}\text { Initial } \\
\text { intensity } \\
(\mathrm{kt})\end{array}$ & $\begin{array}{l}\text { Intensity } \\
\text { change in } \\
-24 \mathrm{~h}(\mathrm{kt})\end{array}$ & $\begin{array}{l}\text { Intensity } \\
\text { change in } \\
+12 \mathrm{~h}(\mathrm{kt})\end{array}$ & $\begin{array}{l}\text { Intensity } \\
\text { change in } \\
+24 \mathrm{~h}(\mathrm{kt})\end{array}$ & $\begin{array}{l}\text { Hours from } \\
\text { the RI } \\
\text { starting time }\end{array}$ & $\begin{array}{c}\text { Hours to } \\
\text { the RI } \\
\text { ending time }\end{array}$ & $\begin{array}{c}\text { Continuing } \\
\text { RI }\end{array}$ & HT \\
\hline Kenna (2002) & 1941 UTC 23 Oct & 79 & 45 & 32.5 & 60 & 26 & 34 & $\sqrt{ }$ & $\sqrt{ }$ \\
\hline Ileana (2006) & 0657 UTC 22 Aug & 52 & - & 20 & 45 & 19 & 35 & $\sqrt{ }$ & $x$ \\
\hline Paul (2006) & 0923 UTC 22 Oct & 45 & 12.5 & 20 & 42.5 & 9 & 27 & $\sqrt{ }$ & $\sqrt{ }$ \\
\hline Felicia (2009) & 2316 UTC 4 Aug & 69 & 40 & 30 & 55 & 29 & 31 & $\sqrt{ }$ & $\sqrt{ }$ \\
\hline Neki (2009) & 0135 UTC 21 Oct & 68 & 32.5 & 25 & 35 & 26 & 28 & $\sqrt{ }$ & $x$ \\
\hline Adrian (2011) & 0714 UTC 9 Jun & 78 & 30 & 30 & 45 & 43 & 29 & $\sqrt{ }$ & $\sqrt{ }$ \\
\hline Dora (2011) & 1016 UTC $20 \mathrm{Jul}$ & 87 & 27.5 & 25 & 45 & 22 & 26 & $\sqrt{ }$ & $x$ \\
\hline Hilary (2011) & 0147 UTC 22 Sep & 48 & - & 30 & 60 & 14 & 40 & $\sqrt{ }$ & $\times$ \\
\hline
\end{tabular}

convective burst was seen by the GOES-E scan at 2015 UTC 17 October ( $2 \mathrm{~h}$ later). Wilma's subsequent RI was more significant and also linked to HTs (Chen and Zhang 2013); however, sampling with the PR appears to have been inadequate because the inner core of Wilma was not captured again after the listed time in Table 6 until 0053 UTC 21 October, when Wilma was weakening.

2) Another situation is when RI is already on going during the TRMM overpass and HTs are not a necessary condition for maintaining the RI. Such TCs with ongoing RI are likely to be fairly well organized (Kaplan et al. 2010) and will continue to intensify unless the environment or the internal process limits it. Nevertheless, if an HT erupts during TC $\mathrm{RI}$, the intensification rate will possibly increase since extra latent heat will be released. This rule is verified by the ECP cases (see rows 1, 4, and 6 in Table 7).

3) There are other factors that also control RI. For example, in contrast to Fang and Zhang (2010) who indicated that the RI of Hurricane Dolly (2008; see row 9 in Table 6) can be ascribed to the upscale vorticity growth mechanism of VHT, Hendricks et al. (2012) suggested that the RI was most likely caused by barotropic instability of the eyewall PV ring and the ensuing PV mixing event.

Apart from the above, according to the SHIPS records, TC Kirk (2012) occurred over a warm ocean with SST of $>28^{\circ} \mathrm{C}$ and TC Fred (2009) was under the influence of low wind shear $\left(<3 \mathrm{~m} \mathrm{~s}^{-1}\right)$ before RI took place, but the internal dynamical processes are unclear. Also, although Hurricane Dean (2007) is famous for two RI processes and two eyewall replacement cycles (Sitkowski et al. 2011), the reason for the first RI process (row 7 in Table 6) has not been discussed.

\section{b. Factors leading to high POFDs/FARs}

High POFDs/FARs indicate that many cases with HTs in the inner core did not ultimately undergo RI.
A reasonable explanation is that the initial conditions were unfavorable. The SHIPS database contains a large amount of synoptic and convection information, so a comparison of the SHIPS variables between RI and nonRI samples based upon a two-sided Behrens-Fisher $t$ test, which assumes unequal sample variances (Dowdy and Wearden 1991), was conducted to pick out the most important conditions. Because the work reported in this section was only concerned with the factors preventing TCs with HTs from RI, the non-RI samples without inner-core HTs were temporarily excluded. Considering the sample size and the precision difference in each basin, if the differences between the mean values of the RI and non-RI samples for a certain variable were statistically significant at the $99 \%$ level in at least three basins, or at the $90 \%$ level in at least four basins, this variable was retained. Following this approach, nearly 20 variables passed the preliminary screening, which could then be divided into one of the four categories below:

1) variables related to radiation, for example, percentage area from 50 to $200 \mathrm{~km}$ of cloud-top brightness temperatures lower than $-10^{\circ}$ (PX10), $-20^{\circ}$, and $-30^{\circ} \mathrm{C}$, with mean values of cloud-top brightness temperatures from different radii;

2) variables linked with SST, for example, RSST, latitude, OHC, MPI, and POT;

3) PER; and

4) variables related to wind shear, for example, 850 $200-\mathrm{hPa}$ vertical shear magnitude with the vortex removed (SHDC).

The variables were highly correlated with each other in each individual category, and thus the most typical variables for each category-PX10, POT, PER, and SHDC-were selected for use. Table 8 shows the average magnitudes of PX10, POT, PER, and SHD for both the RI and non-RI samples in each basin. The differences between the means, as well as the statistical significance of these differences, are also presented in Table 8. It can be seen that statistically significant 


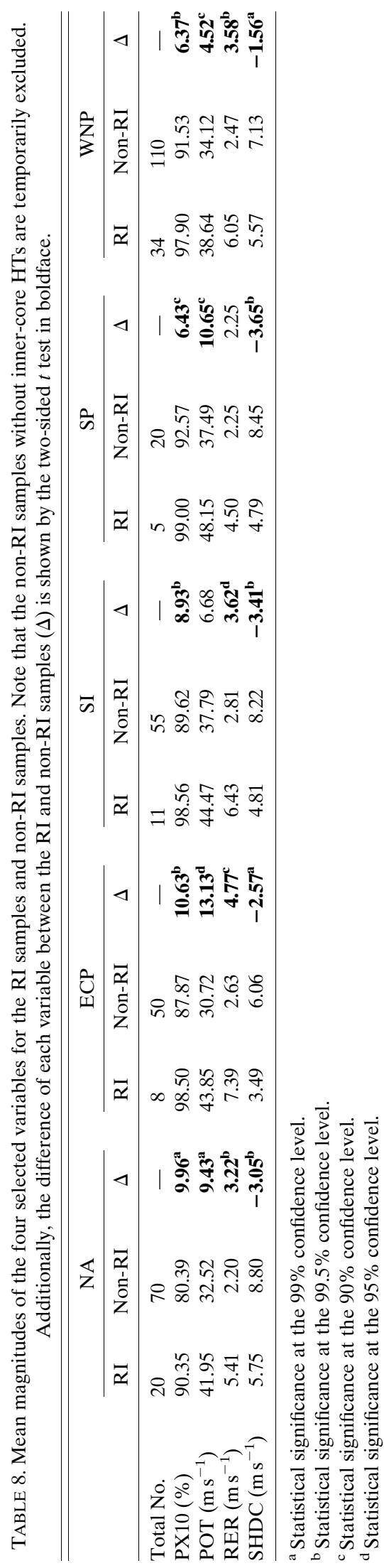

differences were found between the RI and non-RI samples for these four factors for nearly every basin, indicating that they play an important role in modulating RI.

Box-and-whiskers plots in Fig. 5 show the frequency distributions of the RI and non-RI cases for PX10, POT, PER, and SHDC in each of the TC-prone basins. Figure 5 indicates that the distribution of RI cases was more skewed toward high PX10 values than the distribution of non-RI cases. This is consistent with the study of Jiang and Ramirez (2013), who showed that the innercore region must be largely filled with at least moderate convection before RI. The figure also indicates that RI onset needed $65 \%, 85 \%, 95 \%, 95 \%$, and $85 \%$ PX 10 for the NA, ECP, SI, SP, and WNP, respectively, and $25 \%$, $35 \%, 50 \%, 30 \%$, and $15 \%$ of non-RI cases in the NA, ECP, SI, SP, and WNP did not satisfy this criterion.

A notable increase in the fraction of RI cases to non-RI cases was observed for large POT values (Fig. 5, top right) with nearly all RI cases having POT values of $\geq 25 \mathrm{~m} \mathrm{~s}^{-1}$ (only two RI cases in the WNP did not meet the criterion), compared with only about $70 \%$ of non-RI cases in the NA, ECP, SP, and WNP, and $85 \%$ in the SI basin.

Figure 5 also shows notable differences between the distributions of PER for the RI and non-RI samples. All of the RI cases were found with PER values of $\geq 0 \mathrm{~m} \mathrm{~s}^{-1}$, independent of the basin. In contrast, about $30 \%$ of nonRI cases in the NA, $15 \%$ in the ECP and WNP, and $20 \%$ in the SI and SP were weakening during the previous $12 \mathrm{~h}$.

The distributions of SHDC for the RI and non-RI cases (Fig. 5, bottom right) indicate a preference for RI to commence under weaker shear. However, the maximum SHDC acceptable to RI TCs varied across the basins. The maximum SHDC for RI cases in the NA was $12 \mathrm{~m} \mathrm{~s}^{-1}$, and $55 \%$ of non-RI cases had SHDCs above $8 \mathrm{~m} \mathrm{~s}^{-1}$. In the ECP, $100 \%$ of the RI cases occurred when the SHDC was less than $6 \mathrm{~m} \mathrm{~s}^{-1}$, compared to nearly $50 \%$ of the nonRI cases. In the SI, $100 \%$ of RI cases, compared to $50 \%$ of non-RI cases, had SHDC below $8 \mathrm{~m} \mathrm{~s}^{-1}$. There were five RI cases in the SP and all of them had an SHDC of $<6 \mathrm{~m} \mathrm{~s}^{-1}$. In contrast, $70 \%$ of non-RI cases in the SP had SHDCs of $>6 \mathrm{~m} \mathrm{~s}^{-1}$. The maximum SHDC for RI cases in the WNP was $10.5 \mathrm{~m} \mathrm{~s}^{-1}$. Two (about $7 \%$ ) of the RI cases suffered SHDC of $>10 \mathrm{~m} \mathrm{~s}^{-1}$, compared to $20 \%$ of non-RI cases for the WNP.

\section{Reassessment}

In this section, results are presented from using the HT information to predict RI, but with some constrains added to decrease the FAR/POFD. Specifically, the PX10, POT, and PER had to be above their criteria, while the SHDC had to be below; otherwise, RI would 

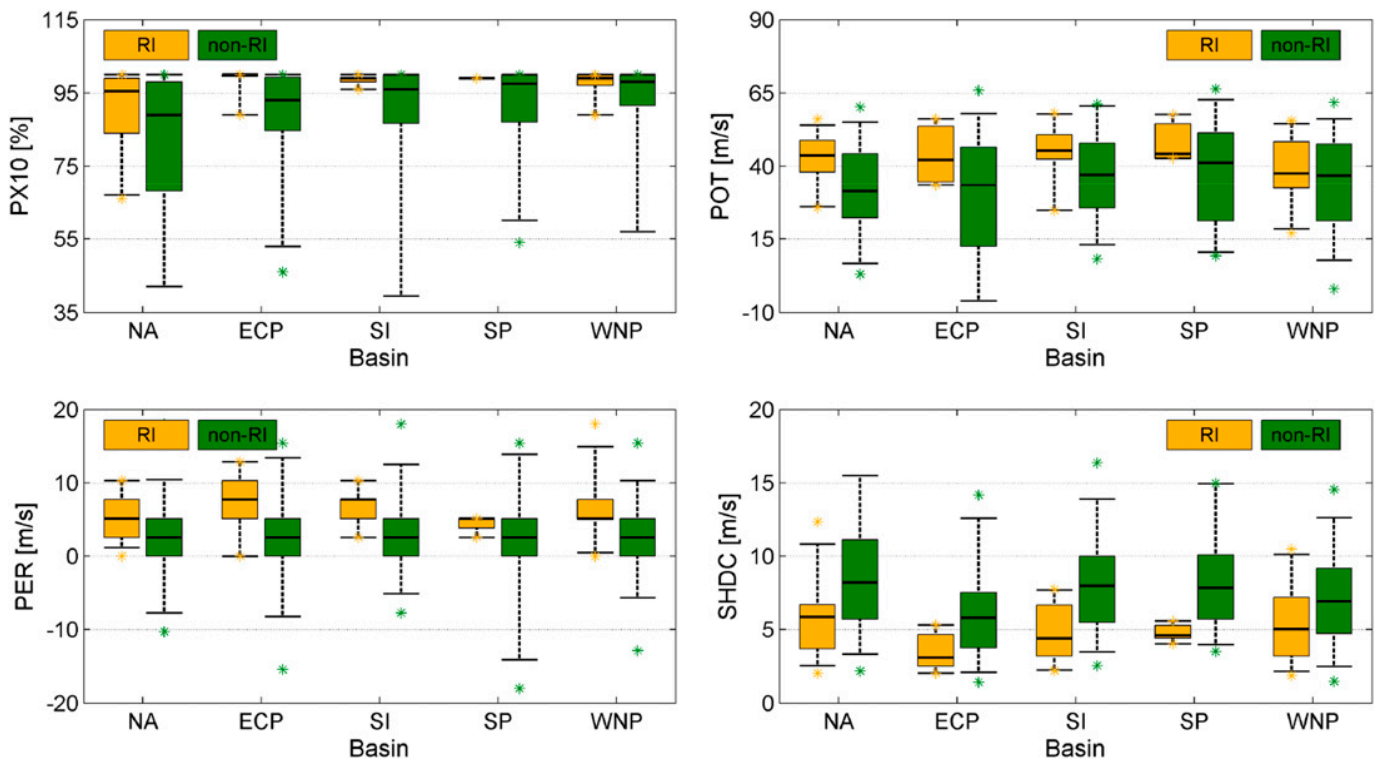

FIG. 5. Box-and-whiskers plots of (top left) PX10, (top right) POT, (bottom left) PER, and (bottom right) SHDC for RI and non-RI samples in each basin. The center line represents the median and the top (bottom) of the box indicates the $75 \%(25 \%)$ percentile. The whiskers extend out to the $5 \%$ or $95 \%$ percentile. The minimum and maximum values are plotted individually with asterisks.

not have commenced, even if an inner-core HT had erupted. The criteria for the four selected factors are listed in Table 9. The criterion for POT (PER) was a constant of $25 \mathrm{~m} \mathrm{~s}^{-1}\left(0 \mathrm{~m} \mathrm{~s}^{-1}\right)$. Since the PX10 and SHDC vary across basins, their criteria were determined based on the mean values plus (or minus) 2 times the standard deviation. Here, the mean and standard deviations were computed using all the RI cases recorded in the SHIPS dataset during 2002-12. Figure 6 shows the reassessment results in each basin.

If predicting RI by combining the $\mathrm{HT}$ information with favorable PX10, the PODs were the same as those determined by using the stand-alone HT, but the POFDs decreased by $8 \%, 7 \%, 5 \%, 7 \%$, and $6 \%$ in the NA, ECP, SI, SP, and WNP, respectively. Therefore, the PSS increments were nearly 0.1 for each basin.

When the POT and PER information was combined with the HTs, the PODs remained unchanged, except for in the WNP. However, the POFDs decreased by at least $10 \%$ for all of the basins. Ultimately, there were four basins whose PSSs increased by 0.1 . The PSS in the WNP only increased by 0.07 due to the fallen POD.

Similarly, when the SHDC information was combined, PODs in the NA and WNP fell by $10 \%$, while PODs in other basins were not influenced. POFDs in all basins were sharply reduced $(19 \%, 14 \%, 20 \%, 10 \%$, and $8 \%$ for the NA, ECP, SI, SP, and WNP, respectively), indicating vertical shear is most important among the large-scale environmental factors. Therefore, all basins except the WNP were found with an increase in PSS.
The PSS in the SI reached 0.48 and the PSS in the SP reached 0.35 .

Finally, we combined all four factors with HT information and predicted the RI again. According to this standard, PODs in the ECP, SI, and SP were unchanged, while POD in the NA decreased by $10 \%$ and POD in the WNP decreased by $15 \%$. POFDs were found with a decrease in all the basins $(30 \%, 25 \%, 25 \%$, $18 \%$, and $21 \%$ in the NA, ECP, SI, SP, and WNP, respectively). As a result, PSSs in all basins improved, with a minimum increase of 0.05 (for the WNP) and a maximum increase of 0.26 (for the ECP). Although PSS in the NA was the lowest, it still reached 0.23. PSS in the SP was as high as 0.56 , which was better than (close to) the PSS of the RII scheme for the NA (ECP). The PSS in the SI was 0.42 , but the statistical significance was suspect because of the small sample size of RI cases. PSS in the WNP, which had the largest sample size, was 0.42 and greater than the PSS value (0.36) without HT inclusion from Shu et al. (2012), demonstrating that a combination of HTs and the RI criteria of the four environmental factors can be useful for the credible prediction of RI.

\section{Conclusions and outlook}

This study demonstrates that RI predictions using inner-core HTs differ depending on the basin. Some RI cases in the NA and ECP were missed with the standalone HT-based RI scheme. These misses can be divided 
TABLE 9. Criteria for POT, PER, PX10, and SHDC in each basin. Here, the mean and standard deviations are computed using all the RI cases recorded in the SHIPS dataset during 2002-12.

\begin{tabular}{|c|c|c|c|c|c|c|}
\hline & & NA & ECP & SI & SP & WNP \\
\hline $\operatorname{POT}\left(\mathrm{m} \mathrm{s}^{-1}\right)$ & Criterion & 25 & 25 & 25 & 25 & 25 \\
\hline $\operatorname{PER}\left(\mathrm{m} \mathrm{s}^{-1}\right)$ & Criterion & 0 & 0 & 0 & 0 & 0 \\
\hline \multirow[t]{3}{*}{ PX10 (\%) } & Mean & 89.61 & 94.98 & 96.82 & 98.07 & 96.39 \\
\hline & Std dev & 13.65 & 8.02 & 5.86 & 3.42 & 6.82 \\
\hline & Criterion & 62.32 & 78.94 & 85.10 & 91.23 & 82.75 \\
\hline \multirow[t]{3}{*}{$\operatorname{SHDC}\left(\mathrm{m} \mathrm{s}^{-1}\right)$} & Mean & 5.05 & 3.80 & 4.88 & 4.90 & 5.59 \\
\hline & Std dev & 2.02 & 1.46 & 1.79 & 1.85 & 2.14 \\
\hline & Criterion & 9.09 & 6.73 & 8.46 & 8.59 & 9.86 \\
\hline
\end{tabular}

into three scenarios: 1) Some RI events may have already begun at 12 or more hours prior to the TRMM overpass, and under these circumstances an inner-core HT is unnecessary. 2) Some RI events driven by non-HT factors (e.g., symmetric heating) are missed when using the inner-core HT as a predictor. 3) HTs are of very short duration, and some RI events are indeed driven by inner-core HTs but the HT has already dissipated or has not occurred at the TRMM overpass time. Meanwhile, as a result of the interaction with high vertical shear and other factors, many TCs with HTs did not ultimately undergo RI. However, the HT-based RI prediction still obtained PSSs greater than 0.3 in the SI and WNP. When RI was predicted with a combination of HTs and four environmental factors, namely PER, POT, PX10, and SHDC, the predictive skill score in the SI was 0.56 . In the NA, ECP, SP, and WNP, the skill scores of RI prediction were $0.23,0.32,0.42$, and 0.42 , respectively, when the HTs were used in conjunction with four environmental factors.

The assessment is based on the 30-kt RI threshold. We have also tested the 25- and 35-kt thresholds (see the supplemental material for further detail) and found that the results for the $35-\mathrm{kt}(25 \mathrm{kt}) \mathrm{RI}$ threshold were better (worse) than those for the 30-kt threshold. However, the common behavior is that the PSSs were all improved with the four environment factors included, relative to the PSSs with the stand-alone HT.

Since RI is a rare event (approximately $9.49 \%$ of cases), there were only a total of 80 global RI cases observed by the TRMM PR during 2002-12. The sample size is even smaller if these RI cases are divided into groups by basin. To generate statistically significant results, it is necessary to conduct an additional assessment when the sample size of the spaceborne-radar TC overpasses has increased to an adequate level. The TRMM
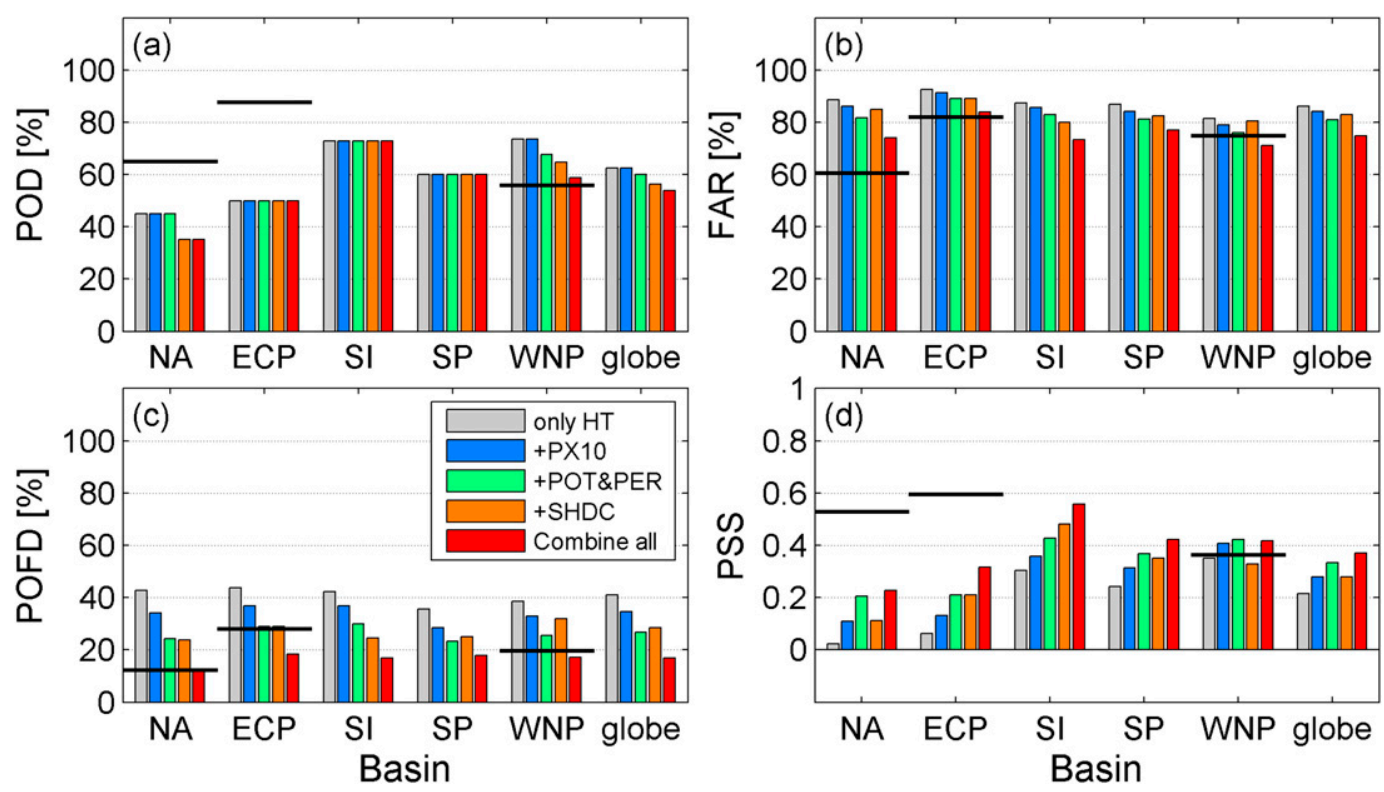

FIG. 6. (a) PODs, (b) FARs, (c) POFDs, and (d) PSSs of RI prediction with HTs by combining the RI criteria of PX10, PER, POT, and SHDC in each basin. The statistical results of RI prediction with RII schemes are also shown (black solid line). 
mission ended in April 2015, but, fortunately, the very successful Global Precipitation Measurement (GPM) mission (Hou et al. 2014) has been in operation. The GPM Core Observatory was deployed in February 2014 and carries a Dual-Frequency Precipitation Radar (DPR), operating at $\mathrm{Ku}$ and $\mathrm{Ka}$ bands (13.6 and $35.5 \mathrm{GHz}$, respectively). Relative to TRMM PR, the DPR is more sensitive to light rain rates and snowfall. Its coverage extends to higher latitudes and provides more accurate cloud-top information. Thus, its data should substantially improve HT-based RI research in the coming years.

Finally, this study excluded all TCs with intensities below tropical storm strength because of the immaturity of TC center determination. However, HTs play an important role in tropical cyclogenesis (Houze et al. 2009). Establishing a simple and accurate center determination method for tropical disturbances and tropical depressions, and assessing the relationship between tropical cyclogenesis and inner-core HTs, are key topics for future research.

Acknowledgments. The authors thank Dr. Jing Xiao of School of Atmospheric Sciences, Nanjing University, for providing valuable suggestions. We would also like to acknowledge two anonymous reviewers for their helpful comments. This work was supported by the National Fundamental Research 973 Program of China (2013CB430100, 2015CB452800) and the National Natural Science Foundation of China (Grants 41275057 and 41105035$)$.

\section{REFERENCES}

Alcala, C. M., and A. E. Dessler, 2002: Observations of deep convection in the tropics using the Tropical Rainfall Measuring Mission (TRMM) Precipitation Radar. J. Geophys. Res., 107, 4792, doi:10.1029/2002JD002457.

Bosart, L. F., C. S. Velden, W. E. Bracken, J. Molinari, and P. G. Black, 2000: Environmental influences on the rapid intensification of Hurricane Opal (1995) over the Gulf of Mexico. Mon Wea. Rev., 128, 322-352, doi:10.1175/1520-0493(2000)128<0322. EIOTRI $>2.0 . \mathrm{CO} ; 2$.

Chan, J. C. L., Y. H. Duan, and L. K. Shay, 2001: Tropical cyclone intensity change from a simple ocean-atmosphere coupled model. J. Atmos. Sci., 58, 154-172, doi:10.1175/1520-0469(2001)058<0154 TCICFA $>2.0 . C O ; 2$.

Chen, H., and D.-L. Zhang, 2013: On the rapid intensification of Hurricane Wilma (2005). Part II: Convective burst and the upper-level warm core. J. Atmos. Sci., 70, 146-162, doi:10.1175/ JAS-D-12-062.1.

Cione, J. J., J. Kaplan, C. Gentemann, and M. DeMaria, 2010: Developing an inner-core SST cooling algorithm for use in SHIPS National Hurricane Center. [Available online at http://www. nhc.noaa.gov/jht/03-05_proj.shtml.]

DeMaria, M., M. Mainelli, L. K. Shay, J. A. Knaff, and J. Kaplan, 2005: Futher improvements to the Statistical Hurricane In- tensity Prediction Scheme (SHIPS). Wea. Forecasting, 20, 531-543, doi:10.1175/WAF862.1.

Dowdy, S., and S. Wearden, 1991: Statistics for Research. 2nd ed. Wiley-Interscience, $555 \mathrm{pp}$.

Dvorak, V., 1995: Tropical clouds and cloud systems observed in satellite imagery: Tropical cyclones. Workbook Vol. 2, 359 pp. [Available from NOAA/NESDIS, 5200 Auth Rd., Washington, DC 20333.]

Fang, J., and F. Zhang, 2010: Initial development and genesis of Hurricane Dolly (2008). J. Atmos. Sci., 67, 655-672, doi:10.1175/ 2009JAS3115.1.

Frank, W. M., and E. A. Ritchie, 2001: Effects of vertical wind shear on the intensity and structure of numerically simulated hurricanes. Mon. Wea. Rev., 129, 2249-2269, doi:10.1175/ 1520-0493(2001)129<2249:EOVWSO > 2.0.CO;2.

Gallina, G. M., and C. S. Velden, 2002: Environmental vertical wind shear and tropical cyclone intensity change utilizing enhanced satellite derived wind information. Preprints, 25th Conf. on Hurricanes and Tropical Meteorology, San Diego, CA, Amer. Meteor. Soc., 3C.5. [Available online at https:// ams.confex.com/ams/pdfpapers/35650.pdf.]

Gettelman, A., P. Hoor, L. L. Pan, W. J. Randel, M. I. Hegglin, and T. Birner, 2011: The extratropical upper troposphere and lower stratosphere. Rev. Geophys., 49, RG3003, doi:10.1029/ 2011RG000355.

Gray, W. M., 1968: Global view of the origin of tropical disturbances and storms. Mon. Wea. Rev., 96, 669-700, doi:10.1175/ 1520-0493(1968)096<0669:GVOTOO>2.0.CO;2.

Guimond, S. R., G. M. Heymsfield, and F. J. Turk, 2010: Multiscale observations of Hurricane Dennis 2005: The effects of hot towers on rapid intensification. J. Atmos. Sci., 67, 633-654, doi:10.1175/2009JAS3119.1.

Hanley, D., J. Molinari, and D. Keyser, 2001: A composite study of the interactions between tropical cyclones and uppertropospheric troughs. Mon. Wea. Rev., 129, 2570-2584, doi:10.1175/1520-0493(2001)129<2570:ACSOTI >2.0.CO;2.

Hence, D. A., and R. A. Houze Jr., 2011: Vertical structure of hurricane eyewalls as seen by the TRMM Precipitation Radar. J. Atmos. Sci., 68, 1637-1652, doi:10.1175/ 2011JAS3578.1.

Hendricks, E. A., 2012: Internal dynamical control on tropical cyclone intensity variability. Trop. Cyclone Res. Rev., 1, 97-105, doi:10.6057/2012TCRR01.11.

- M. T. Montgomery, and C. A. Davis, 2004: On the role of "vortical" hot towers in formation of Tropical Cyclone Diana (1984). J. Atmos. Sci., 61, 1209-1232, doi:10.1175/ 1520-0469(2004)061<1209:TROVHT>2.0.CO;2.

, M. S. Peng, B. Fu, and T. Li, 2010: Quantifying environmental control on tropical cyclone intensity change. Mon. Wea. Rev., 138, 3243-3271, doi:10.1175/2010MWR3185.1.

- B. D. McNoldy, and W. H. Schubert, 2012: Observed innercore structural variability in Hurricane Dolly (2008). Mon. Wea. Rev., 140, 4066-4077, doi:10.1175/MWR-D-12-00018.1.

Heymsfield, G. M., J. B. Halverson, J. Simpson, L. Tian, and T. P. Bui, 2001: ER-2 Doppler radar investigation of the eyewall of Hurricane Bonnie during the Convection and Moisture Experiment-3. J. Appl. Meteor., 40, 1310-1330, doi:10.1175/ 1520-0450(2001)040<1310:EDRIOT > 2.0.CO;2.

Hou, A. Y., and Coauthors, 2014: The Global Precipitation Measurement Mission. Bull. Amer. Meteor. Soc., 95, 701-722, doi:10.1175/BAMS-D-13-00164.1.

Houze, R. A., Jr., W.-C. Lee, and M. M. Bell, 2009: Convective contribution to the genesis of Hurricane Ophelia 
(2005). Mon. Wea. Rev., 137, 2778-2800, doi:10.1175/ 2009MWR2727.1.

Jiang, H., 2012: The relationship between tropical cyclone intensity change and the strength of inner-core convection. Mon. Wea. Rev., 140, 1164-1176, doi:10.1175/MWR-D-11-00134.1.

_- and E. M. Ramirez, 2013: Necessary conditions for tropical cyclone rapid intensification as derived from 11 years of TRMM data. J. Climate, 26, 6459-6470, doi:10.1175/JCLI-D-12-00432.1.

— C. Ciu, and E. J. Zipser, 2011: A TRMM-based tropical cyclone cloud and precipitation feature database. J. Appl. Meteor. Climatol., 50, 1255-1274, doi:10.1175/2011JAMC2662.1.

Kalnay, E., and Coauthors, 1996: The NCEP/NCAR 40-Year Reanalysis Project. Bull. Amer. Meteor. Soc., 77, 437-471, doi:10.1175/1520-0477(1996)077<0437:TNYRP>2.0.CO;2.

Kaplan, J., and M. DeMaria, 2003: Large-scale characteristics of rapidly intensifying tropical cyclones in the North Atlantic basin. Wea. Forecasting, 18, 1093-1108, doi:10.1175/ 1520-0434(2003)018<1093:LCORIT>2.0.CO;2.

$\longrightarrow,-$, and J. A. Knaff, 2010: A revised tropical cyclone rapid intensification index for the Atlantic and eastern North Pacific basins. Wea. Forecasting, 25, 220-241, doi:10.1175/ 2009WAF2222280.1.

Kelley, O. A., and J. B. Halverson, 2011: How much tropical cyclone intensification can result from the energy released inside of a convective burst? J. Geophys. Res., 116, D20118, doi:10.1029/2011JD015954.

_- J. Stout, and J. B. Halverson, 2004: Tall precipitation cells in tropical cyclone eyewalls are associated with tropical cyclone intensification. Geophys. Res. Lett., 31, L24112, doi:10.1029/ 2004GL021616.

Knapp, K. R., M. C. Kruk, D. H. Levinson, H. J. Diamond, and C. J. Neumann, 2010: The International Best Track Archive for Climate Stewardship (IBTrACS). Bull. Amer. Meteor. Soc., 91, 363-376, doi:10.1175/2009BAMS2755.1.

Liu, C., E. J. Zipser, D. J. Cecil, S. W. Nesbitt, and S. Sherwood, 2008: A cloud and precipitation feature database from 9 years of TRMM observations. J. Appl. Meteor. Climatol., 47, 27122728, doi:10.1175/2008JAMC1890.1.

Luo, Z., G. Y. Liu, and G. L. Stephens, 2008: CloudSat adding new insight into tropical penetrating convection. Geophys. Res. Lett., 35, L19819, doi:10.1029/2008GL035330.

Mainelli, M., M. DeMaria, L. K. Shay, and G. Goni, 2008: Application of oceanic heat content estimation to operational forecasting of recent Atlantic category 5 hurricanes. Wea. Forecasting, 23, 3-16, doi:10.1175/2007WAF2006111.1.

McFarquhar, G. M., B. F. Jewett, M. S. Gilmore, S. W. Nesbitt, and T.-L. Hsieh, 2012: Vertical velocity and microphysical distributions related to rapid intensification in a simulation of Hurricane Dennis (2005). J. Atmos. Sci., 69, 3515-3534, doi:10.1175/JAS-D-12-016.1.

Molinari, J., and D. Vollaro, 1989: External influences on hurricane intensity. Part I: Outflow layer eddy angular momentum fluxes. J. Atmos. Sci. 46, 1093-1105, doi:10.1175/1520-0469(1989)046<1093: EIOHIP $>2.0 . \mathrm{CO} ; 2$.

— S. Skubis, and D. Vollaro, 1995: External influences on hurricane intensity. Part III: Potential vorticity structure. J. Atmos. Sci., 52, 3593-3606, doi:10.1175/1520-0469(1995)052<3593: EIOHIP $>2.0 . \mathrm{CO} ; 2$.

Monette, S. A., C. S. Velden, K. S. Griffin, and C. M. Rozoff, 2012: Examining trends in satellite-detected tropical overshooting tops as a potential predictor of tropical cyclone rapid intensification. J. Appl. Meteor. Climatol., 51, 1917-1930, doi:10.1175/ JAMC-D-11-0230.1.
Montgomery, M. T., M. E. Nicholls, T. A. Cram, and A. B. Saunders, 2006: A vortical hot tower route to tropical cyclogenesis. J. Atmos. Sci., 63, 355-386, doi:10.1175/JAS3604.1.

Nguyen, L. T., and J. Molinari, 2012: Rapid intensification of a sheared, fast-moving hurricane over the Gulf Stream. Mon. Wea. Rev., 140, 3361-3378, doi:10.1175/MWR-D-11-00293.1.

Nguyen, M. C., M. J. Reeder, N. E. Davidson, R. K. Smith, and M. T. Montgomery, 2011: Inner-core vacillation cycles during the intensification of Hurricane Katrina. Quart. J. Roy. Meteor. Soc., 137, 829-844, doi:10.1002/qj.823.

NHC, 2008: Joint Hurricane Testbed (JHT) opportunities for transfer of research and technology into tropical cyclone analysis and forecast operations. [Available online at http:// www.nhc.noaa.gov/jht/index.shtml.]

Nolan, D. S., and L. D. Grasso, 2003: Three-dimensional perturbations to balanced, hurricane-like vortices. Part II: Symmetric response and nonlinear simulations. J. Atmos. Sci., 60, 2717-2745, doi:10.1175/1520-0469(2003)060<2717:NTPTBH>2.0.CO;2.

Rappaport, E. N., and Coauthors, 2009: Advances and challenges at the National Hurricane Center. Wea. Forecasting, 24, 395419, doi:10.1175/2008WAF2222128.1.

Reynolds, R. W., and T. M. Smith, 1993: An improved real-time global sea surface temperature analysis. J. Climate, 6, 114-119, doi:10.1175/1520-0442(1993)006<0114:AIRTGS > 2.0.CO;2.

Riehl, H., and J. Malkus, 1958: On the heat balance in the equatorial trough zone. Geophysica, 6, 503-538.

Rogers, R., 2010: Convective-scale structure and evolution during a high-resolution simulation of tropical cyclone rapid intensification. J. Atmos. Sci., 67, 44-70, doi:10.1175/2009JAS3122.1.

Schreck, C. J., III, K. R. Knapp, and J. P. Kossin, 2014: The impact of best track discrepancies on global tropical cyclone climatologies using IBTrACS. Mon. Wea. Rev., 142, 3881-3899, doi:10.1175/MWR-D-14-00021.1.

Schubert, W. H., M. T. Montgomery, R. K. Taft, T. A. Guinn, S. R. Fulton, J. P. Kossin, and J. P. Edwards, 1999: Polygonal eyewalls, asymmetric eye contraction, and potential vorticity mixing in hurricanes. J. Atmos. Sci., 56, 1197-1223, doi:10.1175/ 1520-0469(1999)056<1197:PEAECA > 2.0.CO;2.

_ C. M. Rozoff, J. L. Vigh, B. D. McNoldy, and J. P. Kossin, 2007: On the distribution of subsidence in the hurricane eye. Quart. J. Roy. Meteor. Soc., 133, 595-605, doi:10.1002/qj.49.

Shay, L. K., and J. K. Brewster, 2010: Oceanic heat content variability in the eastern Pacific Ocean for hurricane intensity forecasting. Mon. Wea. Rev., 138, 2110-2131, doi:10.1175/ 2010MWR3189.1.

_ G. J. Goni, and P. G. Black, 2000: Effects of a warm oceanic feature on Hurricane Opal. Mon. Wea. Rev., 128, 1366-1383, doi:10.1175/1520-0493(2000)128<1366:EOAWOF>2.0.CO;2.

Shu, S., J. Ming, and P. Chi, 2012: Large-scale characteristics and probability of rapidly intensifying tropical cyclones in the western North Pacific basin. Wea. Forecasting, 27, 411-423, doi:10.1175/WAF-D-11-00042.1.

Sitkowski, M., J. P. Kossin, and C. M. Rozoff, 2011: Intensity and structure changes during hurricane eyewall replacement cycles. Mon. Wea. Rev., 139, 3829-3847, doi:10.1175/ MWR-D-11-00034.1.

Tao, C., and H. Jiang, 2013: Global distribution of hot towers in tropical cyclones based on 11-yr TRMM data. J. Climate, 26, 1371-1386, doi:10.1175/JCLI-D-12-00291.1.

Wada, A., and N. Usui, 2007: Importance of tropical cyclone heat potential for tropical cyclone intensity and intensification in the western North Pacific. J. Oceanogr., 63, 427-447, doi:10.1007/s10872-007-0039-0. 
Wang, H., and Y. Wang, 2014: A numerical study of Typhoon Megi (2010). Part I: Rapid intensification. Mon. Wea. Rev., 142, 29-48, doi:10.1175/MWR-D-13-00070.1.

Wilks, D. S., 2006: Statistical Methods in the Atmospheric Sciences. 2nd ed. Academic Press, 627 pp.

Willoughby, H. E., 1998: Tropical cyclone eye thermodynamics. Mon Wea. Rev., 126, 3053-3067, doi:10.1175/1520-0493(1998)126<3053: TCET $>2.0 . \mathrm{CO} ; 2$.

- - J. A. Clos, and M. G. Shoreibah, 1982: Concentric eye walls, secondary wind maxima, and the evolution of the hurricane vortex. J. Atmos. Sci., 39, 395-411, doi:10.1175/ 1520-0469(1982)039<0395:CEWSWM >2.0.CO;2.

Wong, M. L. M., and J. C. L. Chan, 2004: Tropical cyclone intensity in vertical wind shear. J. Atmos. Sci., 61, 1859-1876, doi:10.1175/1520-0469(2004)061<1859: TCIIVW $>2.0 . \mathrm{CO} ; 2$.

Zhang, D.-L., and H. Chen, 2012: Importance of the upperlevel warm core in the rapid intensification of a tropical cyclone. Geophys. Res. Lett., 39, L02806, doi:10.1029/ 2011 GL050578. 